\title{
A Comparative Study to Evaluate Antimicrobial Activity of Hydroalchoholic Extract of Garlic and 2\% Chlorhexidine Gluconate Root Canal Irrigant against Enterococcus faecalis (In vitro study)
}

\author{
Manal M. Abdelhafeez ${ }^{1,2^{*}}$ and Nuha Olayan M. Alalweet ${ }^{3}$ \\ ${ }^{1}$ Department of conservative Dentistry, Collage of Dentistry, Qassim University, Kingdom of \\ Saudi Arabia \\ ${ }^{2}$ Department of Endodontics, October University for Modern Sciences and Arts, Egypt \\ ${ }^{3}$ Collage of Dentistry, Qassim University, Kingdom of Saudi Arabia \\ *Corresponding author
}

A B S T R A C T

Enterococcus faecalis is the main pathogen detached from failed root canals and insistent peri-apical lesion. It founds in anatomical structures that remain inside inaccessible areas

Keywords

Enterococcus

faecalis,

Chlorhexidine gluconate, Garlic, Mueller Hinton agar, Irrigants

Article Info

Accepted:

04 November 2018

Available Online:

10 December 2018 for mechanical instrumentation like lateral canal and isthmus so, the root canal irrigation has an important role in the elimination of microbes in these inaccessible areas for instrumentation. Aim of the study is to compare between the efficiency of a newly introduced product of chlorhexidine gluconate as chemical root canal irrigant and hydroalcoholic extract of garlic herbal product against Enterococcus faecalis. This study was In-vitro used the agar diffusion method. Enterococcus faecalis was cultured on blood agar plate. Thirty three plates were divided into two group Positive and negative control used for verification of the results. Chlorhexidine used as a positive control since it is the commonly used irrigate. The zone of inhibition measured and expressed in millimeters. The results of antibacterial activity were expressed in terms of the diameter of the zone of inhibition. Statistical package for social sciences (SPSS) was used to analyze the data. A descriptive statistics calculated the efficiency of the irrigation solution against Enterococcus faecalis. Student's T-Test was used. The efficacy of chlorhexidine gluconate was found to be significantly more $(18.31 \pm 0.946)$ than Garlic extract $(14.71 \pm 0.985)$ against Enterococcus faecalis and the difference was statistically significant $\mathrm{p}<0.05 .2 \%$ chlorhexidine gluconate was shown to inhibit the Enterococcus faecalis effectively. But garlic extract (allicin) as compare to chlorhexidine showed very minimal activity against E. faecalis.

\section{Introduction}

Enterococcus faecalis is the main pathogen detached from failed root canals and insistent peri-apical lesion. ${ }^{(1)}$. There is a great difficulty to eradicate the microorganism from infected root canal especially inside an anatomical structure that remains inaccessible 
for mechanical instrumentation like lateral canal and isthmus. Therefore the root canal irrigation has an important role in the elimination of microbes in these inaccessible areas for instrumentation. ${ }^{(2-4)}$ One of the irrigant that was frequently used is chlorhexidine gluconate (Figure 1), Wang C.S et al 2007 monitored high activity of chlorhexidine against E. feacalis. But When tested in vivo showed less ability in dissolving necrotic tissue remnants coupled by poor antimicrobial activity, this way there were many trials to add some surface modifier and the wetting agent to increase the effectiveness of these irrigants. ${ }^{(5)}$

Herbal product have become more popular in dentistry because of its availability, low toxicity, cost-effectiveness, lack of microbial resistance and increase shelf life. ${ }^{(6)}$ Garlic one of the herbal product which is bulbous perennial medicinal plant and allicinit's main active component. Some studies confirm high benefit in destroying cell wall and membrane of root canal bacteria. Therefore it's widely used in medicine for its antibacterial, antifungal, antiviral, anti-mutagenic, antioxidative, anti-cancerous, anti-aging, immunomodulatory effects. ${ }^{(7)}$ However, no studies showed that the garlic herbal product can be used as an alternative to chemical irrigation. The present study aimed to compare between the efficiency of a newly introduced product of chlorhexidine gluconate as chemical root canal irrigant and hydroalcoholic extract of garlic herbal product against Enterococcus faecalis using the commonly used agar diffusion method.

\section{Materials and Methods}

Assay of antimicrobial activity of garlic (Allium sativum L.) extract against Enterococcus faecalis micro-organism. Fresh garlic bulbs (Allium sativum L.) surface was sterilized by using ethanol, the ethanol was evaporated in a sterile laminar flow chamber.
By using a sterile mortar and pestle the garlic was homogenized, the homogenized mixture of garlic was filtered and diluted to different concentrations with suitable volumes of sterile distilled water other additives with being used for preparation. Agar well diffusion method was used to conduct the antimicrobial susceptibility test ${ }^{(8)}$

Enterococcus faecalis was cultured on blood agar plate (Figure 2). 20\% concentration of the prepared garlic extracts (Figure 3) was made using distilled water. Chlorhexidine will be the positive control since it is the commonly used irrigant and has excellent antimicrobial activity against $E$. faecalis micro-organism. Positive and negative control was used for verification of the results. The number of agar media plates was thirty three divided into two groups.

Plates was inoculated with the organisms by even streaking of the swab over the entire surface of the plate three times, rotating the plate approximately $60^{\circ}$ after each application to ensure an even distribution of the inoculums. Three wells of $5 \mathrm{~mm}$ size was made with a sterile borer into each agar plate containing the bacterial inoculums. $20 \mu \mathrm{l}$ volume of each extract concentration was dispensed into the wells of inoculated plates. Then the incubated for $24 \mathrm{~h}$ at $37^{\circ} \mathrm{C}$. The zone of inhibition was measured and expressed in millimeters. The antibacterial activity results were expressed in terms of the diameter of the zone of inhibition ${ }^{(9,10)}$. The mean and standard deviation of the diameter of the inhibition zones were calculated (Figure 4).

\section{Statistical analysis}

Data was analyzed using statistical package for social sciences (SPSS). A descriptive statistics was used to calculate the efficiency of the irrigating solution against Enterococcus faecalis using Student's T-Test. 


\section{Results and Discussion}

Student t-test was used to compare the efficiency of a newly introduced product of chlorhexidine gluconate as chemical root canal irrigant and hydroalcoholic extract of garlic herbal product against Enterococcus faecalis using the commonly used agar diffusion method. The efficacy of chlorhexidine gluconate was found to be significantly more $(18.31 \pm 0.946)$ than Garlic extract (14.71 \pm 0.985$)$ against Enterococcus faecalis (Table 1) and the difference was statistically significant $\mathrm{p}<0.05$.

Table.1 Mean, Std. Devation, t-value and p-value of garlic extract and CHX

\begin{tabular}{|l|l|l|l|l|l|}
\hline Groups & $\mathbf{N}$ & Mean & $\begin{array}{l}\text { Std. } \\
\text { Deviation }\end{array}$ & $\begin{array}{l}\text { t- } \\
\text { value }\end{array}$ & $\begin{array}{l}\text { p- } \\
\text { value }\end{array}$ \\
\hline garlic extract & 17 & 14.71 & $\mathbf{. 9 8 5}$ & - & $\mathbf{0 . 0 0 0}$ \\
\hline Chlorhexidine & 16 & 18.31 & $\mathbf{. 9 4 6}$ & $\mathbf{1 0 . 7 1 2}$ & \\
\hline
\end{tabular}

Figure.1 CHX - pluse $^{\mathrm{TM}}$ 2\% Chlorhexidine gluconate solution enhanced with surface modifier and wetting agents

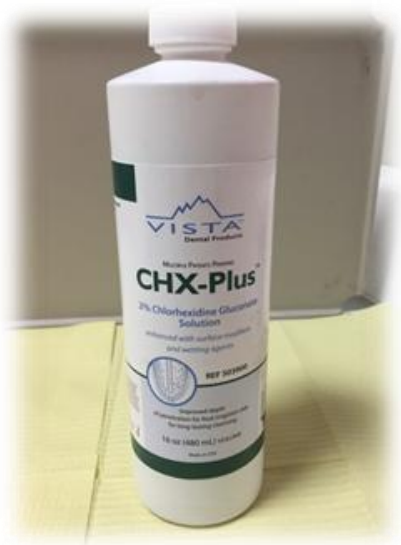

Figure.2 A. Enterococcus faecalis was cultured on blood agar plate B. Enterococcus faecalis
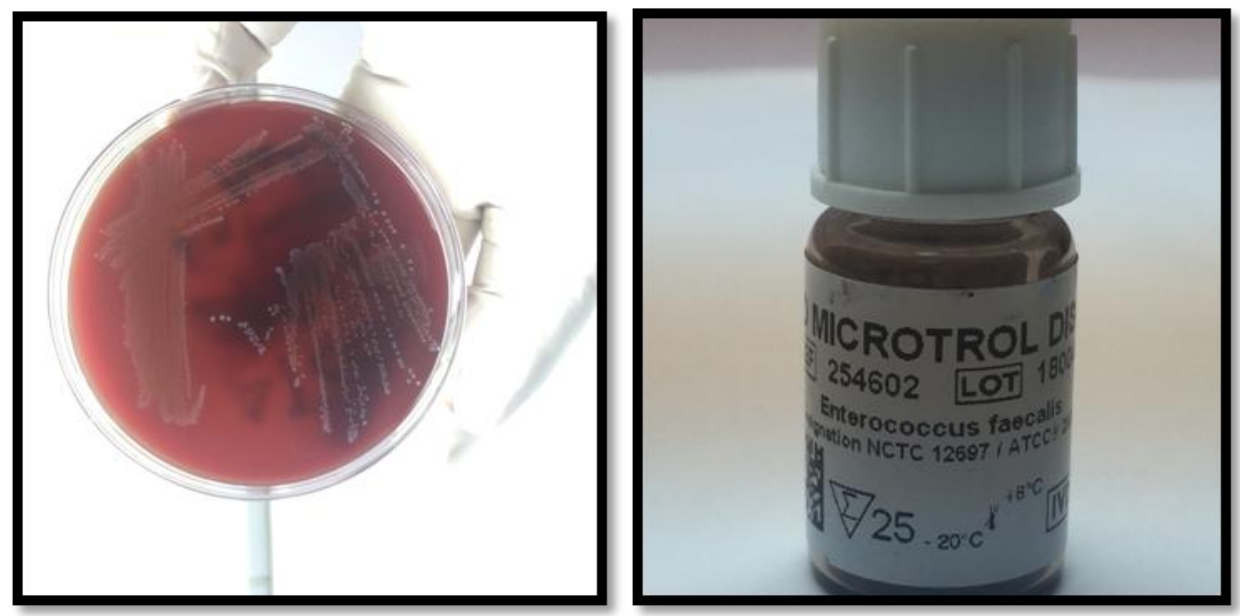
Figure.3 20\% concentration of the prepared garlic extracts

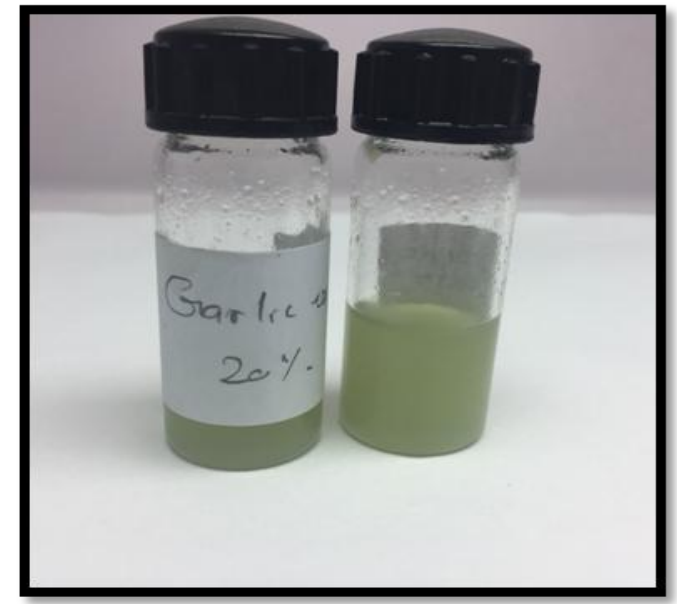

Figure.4 2\% chlorhexidine was shown to inhibit the Enterococcus faecalis effectively

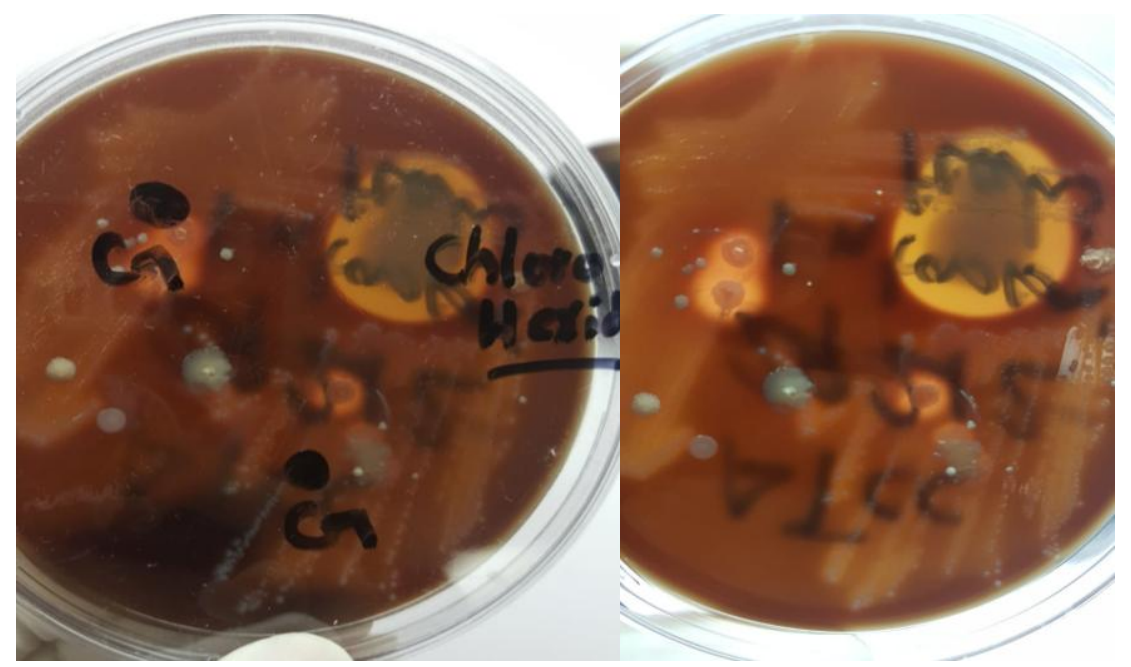

Graph.1 show inhibition zone in $\mathrm{mm}$ of $\mathrm{CHX}$ and garlic.

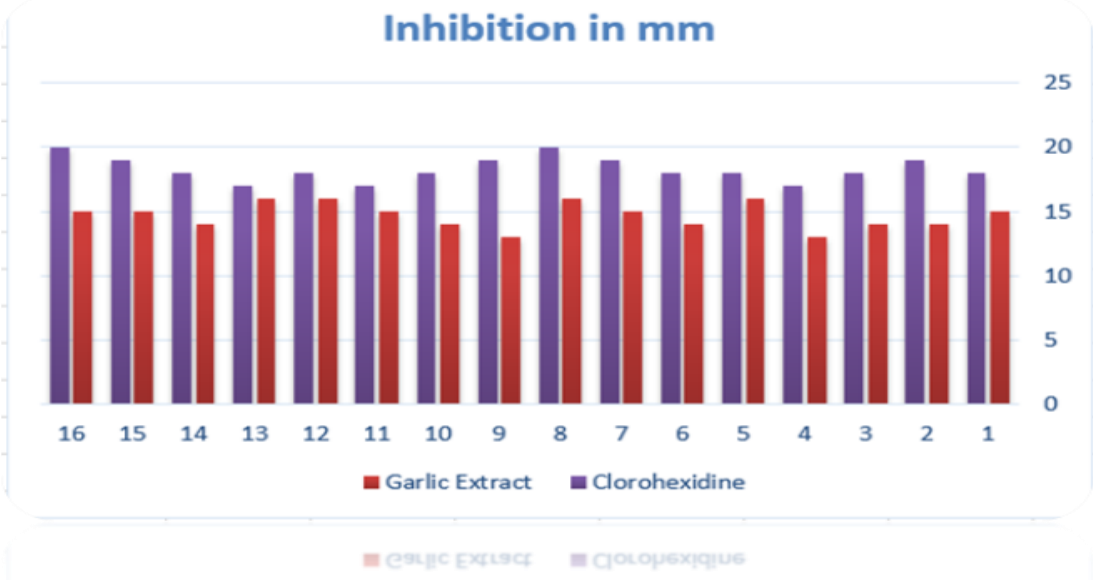


The main objective of root canal treatment is to eradicate the microorganisms from the root canal and to prevent their recontamination in the post-treatment period. In the anatomically challenging areas like fins, lateral or furcal canals, apical deltas, webs and isthmus the biofilm may remain undisturbed after mechanical debridement. Therefore, in order to ensure complete purity of the canal system, it is necessary to use irrigant solutions to complement the action of the mechanical instruments ${ }^{(11)}$ Enterococcus feacalis had frequently been isolated from root canals of failed endodontic treatment cases ${ }^{(12)}$.

In the present study, $2 \%$ chlorhexidine was shown to inhibit the Enterococcus faecalis effectively. But garlic extract as compared to chlorhexidine showed very minimal activity against Enterococcus faecalis. Chlorhexidine gluconate $(2 \%)$ is a good disinfecting agent with a property of substantively contributing to its prolonged time of action ${ }^{(13)}$. But the major disadvantage persisting is its inferior tissue dissolving action as a primary endodontic irrigant ${ }^{(14)}$. Allicin, the active ingredient of garlic, acts by partially inhibiting DNA and protein synthesis and also totally inhibiting RNA synthesis as a primary target ${ }^{(15)}$.

Under the conclusion of this study which evaluated the antimicrobial potential of chemical agent 2\% chlorhexidine and herbal Garlic extract" Allicin" when used as root canal irrigants against Enterococcus faecaliswe concluded that the herbal extract had shown statistically significant activity against Enterococcus faecalis which was less than that of $2 \%$ chlorhexidine. Chlorhexidine had demonstrated the best results as compare to the herbal one. But further evaluation of the antimicrobial efficacy of Garlic is highly recommended before extensive clinical usage.

\section{Recommendation}

Vivo studies are needed to evaluate garlic efficiency against $E$. feacalis with high concentration.

Conjunction of garlic to be used with chemical irrigant to get the best efficiency against E. feacalis.

\section{Acknowledgment}

The author would like to thank Dr. Rahul Gaikwad for help with the statistical analysis and Dr. Dalia Ahmed, Dr.Eman Ibrahim Basha Clinical pathology specialist Microbiology department and Dr. Hamdoon H. Mohammed. Assistant Professor of Pharmacognosy and Medicinal Plant Chemistry for help with preparations for the study.

\section{References}

1.Gomes BP, Pinheiro ET, Jacinto RC, Zaia AA, Ferraz CC, Souza-Filho FJJ Endod. 2008 May; 34(5):537-40.

2.ElKarim I, Kennedy J, Hussey D:The antimicrobial effects of root canal irrigation and medication. Oral Surg Oral Med Oral Pathol Oral Radiol Endod: 2007;103:560-9

3.Ng YL, Mann V, Rahbaran S, Lewsey J, Gulabivala K IntEndod J: Outcome of primary root canal treatment systematic review of the literature -- Part 2. Influence of clinical factors: 2008 Jan; 41(1):6-31.

4.Zehnder. M J Endod: Root canal irrigants: 2006 May; 32(5):389-98.

5-Wang C.S, Arnold RR, Trope M, Teixeira FB.Clinical efficiency of $2 \%$ chlorhexidine gel in reducing intracanal bacteria. J Endod: 2007;33(11):1283-89

6.Oncag O, Cogulu D, Uzel A, Sorkun K: Efficacy of propolis as an intracanal 
medicament against Enterococcus faecalis. Gen Dent 2006; 54: 319-22.

7.Capasso A.: Antioxidant action and therapeutic efficacy of Allium sativum L. Molecules: 2013; 18: 690-700.

8.Leonardo MR, da Silva LA, Tanomaru Filho M, Bonifácio KC, Ito IY: In vitro evaluation of antimicrobial activity of sealers and pastes used in endodontics. J Endod: 2000;26:391-4

9.Prabhakar J, Senthilkumar M, Priya MS, Mahalakshmi K, Sehgal PK, Sukumaran VG. Evaluation of antimicrobial efficacy of herbal alternatives (Triphala and green tea polyphenols), MTAD, and 5\% sodium hypochlorite against Enterococcus faecalis biofilm formed on tooth substrate: An in vitro study. $\mathrm{J}$ Endod 2010; 36: 83-6.

10.Mohammadi Z. and Abbott P. V. Antimicrobial substantivity of root canal irrigants and medicaments: a review. Aust Endod J: 2009: 35, 131139.

11. Gomes BPFA, Vianna ME, Sena NT: In vitro evaluation of antimicrobial activity of calcium hydroxide combined with chlorhexidine gel used as intracanal medicament. Oral Surg Oral Med Oral Pathol Oral RadiolEndod.2006; 102:544-50.

12. Stuart $\mathrm{CH}$, Schwartz SA, Beeson TJ, Owatz CB. Enterococcus faecalis: its role in root canal treatment failure and current concepts in retreatment. $J$ Endod. 2006; 32(2): 93-98.

13. M. Zehnder. Root canal irrigants. $J$ Endod.: 2006; 32(5):389-98.

14. Borges FC, de Melo MS, Lima JM, Zanin IJ, Rodrigues LA: Antimicrobial effect of chlorhexidine digluconate in dentin: in vitro and in situ study. $J$ Conserv Dent.2012; 15: 22-26.

15. Eja ME, AsikongBE, Abriba C, Arikpo GE, Anwan EE, Enyi-Idoh KH. A comparative assessment of the antimicrobial effects of garlic (Allium sativum) and antibiotics on diarrheagenic organisms. Southeast Asian J Trop Med Public Health: 2007; $38: 343-8$

\section{How to cite this article:}

Manal M. Abdelhafeez and Nuha Olayan M. Alalweet. 2018. A Comparative Study to Evaluate Antimicrobial Activity of Hydroalchoholic Extract of Garlic and 2\% Chlorhexidine Gluconate Root Canal Irrigant Against Enterococcus faecalis (In vitro study). Int.J.Curr.Microbiol.App.Sci. 7(12): 359-364. doi: https://doi.org/10.20546/ijcmas.2018.712.044 